\title{
Graduate and undergraduate students' views on learning and teaching physics
}

\author{
Gyoungho Lee and Lei Bao \\ Dept. of Physics, The Ohio State University, $174 \mathrm{~W} .18^{\text {th }}$ Avenue, Columbus, OH 43210
}

This study describes graduate and undergraduate students' views on learning and teaching physics. We conducted this research with thirteen junior-level graduate students and four undergraduate students using web-based surveys and interviews. The results indicate that most graduate students use themselves as 'templates' for good learning methods and implemented them in their teaching practice expecting that the undergraduate students could do the same. On the other hand, undergraduate students have difficulties in learning physics and they need different teaching approaches from traditional methods.

\section{INTRODUCTION}

Many researchers have studied teachers' views on science teaching/learning. Existing results indicate that science continues to be taught much the way it has always been ${ }^{1}$. Several studies found that when prospective teachers start their university education, they bring ideas, conceptions, and attitudes about science learning/teaching from their many years' experience at school ${ }^{2,3,4}$. These views in many respects do not change significantly during the university education program ${ }^{5}$. The implication of this research is that teachers and prospective teachers (as university students) coming into classes bring a well established set of views on how students learn and what strategies may be best applied in a teaching-learning process. In addition, these views continue to affect their learning and teaching.

However, there has been less research on the way that students in higher education conceive of learning and teaching physics. Thus, as a preliminary study of this issue, we investigated graduate and undergraduate students' views on learning and teaching physics.

\section{RESEARCH CONTEXT}

At the Ohio State University, 13 graduate students (3 females and 10 males) and 4 undergraduate students (3 females and 1 male) participated in this study voluntarily. All graduate and two undergraduate students majored in physics. Two undergraduate students ( 1 female and 1 male) majored in chemical and electrical engineering respectively and they took introductory physics courses before this study.

In order to measure graduate and undergraduate students' views on learning and teaching, the authors developed and used web-based surveys and semi-structured interviews.

The research focused on seven topic areas: definition of learning, learning approach/strategies/habits, factors that affect learning, expected students' learning, teaching plan, expected teaching, and learning motivation. Since individual views are dynamic and depend on the particular context, we used specific context to investigate students' views on learning and teaching. For instance, after asking students to propose their general definition of learning "How would you know if you had learned something in a physics course?", students were asked to give 3-5 examples of the types of strategies/approaches/habits that they often use in learning physics. We also ask students to recall their experience as undergraduate students taking physics courses and discuss their approaches that 
they used to learn different topics (e.g., introductory mechanics, E \& M, etc.).

\section{RESULTS}

Based on the student data, we were able to characterize these students' views with five categories shown in table 1. Graduate students' views on learning and teaching were divided into three qualitatively different types and undergraduate students' views were divided into two types respectively. These types were categorized based on three criteria: motivation (motivation in learning physics), learning (definition of learning, learning approach/strategies/habits, and factors that affect learning), and teaching (expected teaching and teaching plans).

For example, a student in type G-I would have high motivation to learn physics (considering physics as the most interesting and important subject, and main major). The students will focus on using basic learning approaches namely, reading textbooks, taking notes, solving problems and discussing with other students. He/she often has his/her own ways of learning that are less affected by a course format and does extra learning activities: reading many books that explain background history and context of a topic. On teaching, this student has not only a basic teaching plan (encouraging students to read books, to solve many problems, and to do experiments), but also suggests extra teaching activities based on historical and student-centered perspectives.

The differences between types G-II and the previous type are in the learning approaches and teaching plan. Students in this type just use basic learning approaches. They think it is enough, since it works well for them. Their teaching plan is to support and encourage students to follow basic learning approaches that they use. It seems to be simple and close to traditional views.

Table 1. Graduate and undergraduate students' views on learning and teaching

\begin{tabular}{|l|l|l|l|l|}
\hline Types & Motivation & Learning & Teaching & Student ID \\
\hline G-I & $\begin{array}{l}\text { High } \\
\text { motivation to } \\
\text { learn physics }\end{array}$ & $\begin{array}{l}\text { Basic learning approaches + extra } \\
\text { activities } \\
\text { (learning by self) }\end{array}$ & $\begin{array}{l}\text { Basic teaching } \\
\text { plan + extra } \\
\text { activities }\end{array}$ & 3 \\
\hline G-II & $\begin{array}{l}\text { High } \\
\text { motivation to } \\
\text { learn physics }\end{array}$ & $\begin{array}{l}\text { Just using } \\
\text { basic learning approaches } \\
\text { (learning by self) }\end{array}$ & $\begin{array}{l}\text { Basic teaching } \\
\text { plan }\end{array}$ & $\begin{array}{l}2,4,5,6, \\
7,10,11, \\
12,13\end{array}$ \\
\hline G-III & $\begin{array}{l}\text { High } \\
\text { motivation to } \\
\text { learn physics }\end{array}$ & $\begin{array}{l}\text { Basic learning approaches } \\
\text { (with conflicts between } \\
\text { understanding and passing the } \\
\text { course) }\end{array}$ & $\begin{array}{l}\text { Basic teaching } \\
\text { plan + extra } \\
\text { activities }\end{array}$ & $1,8,9$ \\
\hline U-I & $\begin{array}{l}\text { Moderate } \\
\text { motivation to } \\
\text { learn physics }\end{array}$ & $\begin{array}{l}\text { Following course format + some } \\
\text { extra activities } \\
\text { (with difficulties) }\end{array}$ & $\begin{array}{l}\text { Basic teaching } \\
\text { plan + extra } \\
\text { activities }\end{array}$ & A, B \\
\hline U-II & $\begin{array}{l}\text { Low } \\
\text { motivation to } \\
\text { learn physics }\end{array}$ & $\begin{array}{l}\text { Following course format/ just } \\
\text { doing home work } \\
\text { (with difficulties) }\end{array}$ & $\begin{array}{l}\text { Basic teaching } \\
\text { plan }\end{array}$ & C, D \\
\hline
\end{tabular}

* G: Graduate, ** U: Undergraduate 
Students in type G-III have experienced difficulties in learning, even though they have high motivation to learn physics. They often struggle to solve the conflict between understanding physics concepts and passing the exam. They also propose not only basic teaching plan but also extra teaching activities based on their experiences with certain methods that would help them.

Students in type U-I also have difficulties in learning physics. They have moderate motivation (they like physics and enjoy studying it). They often struggle to solve the conflict between understanding physics concepts and passing the exam. They often do some extra learning activity (reading books except for a textbook) following with a course format. They propose not only a basic teaching plan but also extra teaching activities based on their experiences of learning.

The differences between type U-II and type U-I are in learning motivation, learning approaches and teaching plan. Since the main motivation of the students with U-II is to pass the physics courses that were required, their learning is seen to just do homework without understanding physics concepts well. They do not have specific ideas on teaching physics and will simply follow basic teaching approaches.

In the following, we show one example with the actual questions and responses of a graduate student identified as type G-II.

\section{$\underline{\text { Motivation }}$}

Q: Please describe your reason to take physics as the field for your graduate study and your interest areas in physics.

S: "I consider physics as a most interesting and important natural science... Development of the humanity depends on it. I'm not refusing that it depends also on other things but physics is very global science, from elementary particles to giant galaxies. It includes everything nature deals with. My majority interested areas are experimental high energy and particle physics."

\section{Learning}

Q: Please give 3-5 examples of the types of learning strategies/approaches/habits that you often use in learning physics.

S: "Reading the theory in details, solving problems, discussions with colleagues, and relating the subject to everyday problem."

Q: If you used different approaches in learning physics and other topics, what are the significant factors that made you use different approaches in learning. You may think about issues like the nature of physics knowledge, course format, teacher's teaching methods, etc.

S: "The essential part in learning physics is solving problems. While in other areas, solving problems is not the most important part (if it exists at all). To improve knowledge in physics people solve problems, to improve their language skills people try to speak that language a lot, to improve knowledge in psychology people analyze others..."

Q: What are the learning approaches that undergraduate students need to develop and emphasize in order to learn physics better?

S: "1. Deep knowledge of basic theory is essential. This comes by reading books. 2 . Application of this knowledge by solving problems, which is very important in developing and improving solving skills. 3. Laboratories, which will provide students at least some experience. 4. Discussions with other students as well as tutors and teachers. That's a way to learn something new, and to improve knowledge you already have. These are the most important learning strategies... 'Thinking for themselves' would be probably the most important issue.

Teaching

Q: Suppose you are a teacher with complete freedom of structuring your instruction in the context of a mid-sized class $(\sim 50$ students) on intro-mechanics in a large university, which is very supportive to 
education. Propose a teaching plan for the structure of the instruction for this course.

S: "Regular lectures and recitations. I would also add some sort of seminars, where students would be assigned to solve a problem or to give some talk on a particular topic. And I would try to include all my students in that. That way they would be more prepared and interested (hopefully). Besides I'd have a chance to evaluate every student myself on a basis of his or her presentation. Questions of the audience (fellow students) would be highly encouraged. In other words, I'd try to create an atmosphere, where students work for themselves, and I just instruct and help them in that. That fact that they should make a presentation in front of the whole class should make them feel responsible and learn better. And of course, regular labs."

Q: As an instructor, what approaches in teaching and learning would you implement and/or emphasize to help students understand physics better?

S: "Encouraging students to think for themselves and come up with answers is very helpful I think. Discussions with the class. Encouraging making projects and presentations. Performance of labs. Solving as much problems as possible. Do quizzes quite often (though, they will hate me for that, but it will force them to prepare much more profound every time)."

\section{CONCLUSION}

The most frequent type of graduate students' views on learning and teaching was G-II. Students in this type use their own experiences as 'templates' for good learning methods and implemented them in their teaching practice expecting that undergraduate students could do the same. Although the graduate students are successful with their learning methods, they often overlook the difficulties and needs of the general population of undergraduate students. As we can see in the results of this study, all of the undergraduate students we interviewed (we only have a small sample) have difficulties in learning physics and need different teaching approaches that address their difficulties.

In conclusion, we found that there is a mismatch between graduate students' major views and undergraduate students' views on learning and teaching physics. Since graduate students are an important force in teaching introductory physics courses in universities, we have to carefully consider their views on learning and teaching and any possible impact on the ways they use to teach undergraduate students.

\section{ACKNOWLEDGEMENTS}

We thank the Physics Education Research group at The Ohio State University for their helpful comments. This work is supported in part by NSF grant \#REC0087788.

${ }^{1}$ J. A. Thomas and J. E. Pedersen, "When do science teachers learn to teach? A comparison of school children's and preservice teachers' science teacher illustrations," Annual Meeting (AETS, Costa Mesa, CA, 2001).

${ }^{2} \mathrm{C}$. Briscoe, "The dynamic interactions among beliefs, role metaphors, and teaching practices: A case study of teacher change," Sci. Educ. 75, 185-163 (1991).

${ }^{3}$ R. F. Gunstone, M. Slattery, J. R. Bair, and J. R. Northfield, "A case study exploration of development in preservice science teachers," Sci. Educ. 77, 47-73 (1993).

${ }^{4}$ B. J. Gustafson and P. M. Rowell, "Elementary preservice teacher: Constructing conceptions about learning science, teaching science and the nature of science," Int. J. Sci. Educ. 17, 585-605 (1995).

${ }^{5}$ M. F. Pajares, "Teachers' beliefs and educational research: Cleaning up a messy construct," Rev. Ed. Res. 62, 307-332 (1992). 